\title{
Color Preference in Luxury Electrical Appliances
}

\author{
Ibarra Gutiérrez, Laura Edith", Rosales Cinco, Rosa Amelia, Prado León, Lilia Roselia \\ University Center of Art, Architecture and Design, University of Guadalajara, Mexico
}

Copyright $\bigcirc 2017$ by authors, all rights reserved. Authors agree that this article remains permanently open access under the terms of the Creative Commons Attribution License 4.0 International License

\begin{abstract}
Objects are signs which transmit social, political, religious, economic or cultural messages, among others. The meanings of these messages are directed from the emitting object to the recipient, the person who uses or owns the item. The aim of this research is to determine which colors the population of Guadalajara, Mexico relates to luxury in the case of electrical appliances. The study was based on a Product Personality Profiling (PPP) evaluation of six appliances. The features of those products represent a social-economic level which is linked to the consumer of luxury objects. The target of the survey was to determine the colors that represent the luxurious electronic appliance market, which could be linked to a luxury car. The colors in the survey (all metallic versions) were sand, silver, black, blue, grey, white, green and "other." Participants chose two colors for the luxury objects. Silver was chosen for the first three and metallic black for the last three. The results show that the colors silver and black are related to luxury and that the remaining colors are less likely to be related to luxury appliances.
\end{abstract}

Keywords Color Associations and Preference, Electrical Appliances, Luxury

\section{Introduction}

Design is a component of social endeavors to develop life-style ideas. It aims to create realities comprised of objects, basing itself on the social needs of the public. Psychology and sociology are disciplines which analyze and make sense of the needs and behaviors of users who, in turn, form populations. Objects are social markers and to design them it is convenient to understand them from the standpoint of the social context and culture for which they will be created. The choice of a product from among a variety of the same category is mainly based upon two formal variables related to the design of an object: shape and color. One object is differentiated from another by its shape and two objects of the same shape, but not of the same color, are considered different, each with its own symbolic interpretation.

\subsection{Color Associations and Preference}

Color is the second formal component of design, of a lower rank than shape, but still playing an important role. People are used to selecting a product principally because of its shape, but many times it is its color which influences the final selection because different colors attract different personalities, due to the fact that colors are psychological and social markers. Color works like an information-bearing code for the recipient and in every culture it is associated with emotions and concepts. Color is associated with hot and cold temperature, depending on its wavelength in nanometers. Contrast is the harmony of color based on a geometric and mathematical pattern of the color wheel. Also related to color are emotions, for example when a person feeling sad or depressed says, "I'm blue." In addition, it is associated with gender. Some cultures use pink for products directed toward girls and blue for boys. In toy stores, blue-grey tones notably dominate aisles for boys while pink and lilac color those for girls. In order to distinguish one object from another, for example company brands, color acts as a differential, marking the products of a specific brand. A certain brand of shampoo, for example can easily be located by color. Another factor marked by color is hierarchy. In many cultures, the color gold means money, happiness and luxury [1]. Finally, color is associated with concepts. For example, green and ocher design styles are related to sustainable or ecological products.

In color perception it must be considered that meaning and preference will vary from one culture to another [2]. Sparke mentions that in the 1980s Japan, followed by Taiwan, Singapore, Indonesia and China, designed and sold televisions adapted to each country after discovering the varieties needed for these markets. In Germany they liked the color black, while in Italy white was preferred and in the United Kingdom they wanted a faux wood-grain pattern.

Many studies of the meanings of color have been carried out in isolated stimulus-response situations with no application to concrete objects or products. Along these lines we have found no research which relates elegance or luxury to the colors of home appliances, the target of this present study. In stimulus-response studies it has been observed over several decades that the color associated with elegance has 
been black [3]. [4] Eiseman (2000) adds wine, silver and gold. Likewise, [1] reports black, silver, gold and white, agreeing in great part with the previous studies.

More recently,[5] mention that black is associated with sophistication and power, while gold, silver and copper are associated with wealth, royalty and nobility, all of them concepts related to luxury.

[6] discovered in their research that navy blue, desaturated dark blue, wine, rose and reddish brown (Munsell Code 5PB 3/6, 10B 4/4, 5R 4/10, 10RP 6/6 and 2.5R 3/4 respectively) are associated with elegance. The results of this study indicated colors different from those which traditionally have been associated with elegance, perhaps due to the use of nine colors at three different levels of saturation and brightness.

\subsection{Electrical Appliances}

Electrical appliances were introduced into the home during the XIX century when the power grid became widespread. They were designed to make domestic chores easier and mitigated the effects of the disappearance of servants. The modern idea of this technology was introduced to promote hygiene and the scientific organization of work [7]. These new artifacts were not available to all social groups and only the higher classes could afford to buy them. In the 1930s they were so expensive that they were considered luxury items, but by the 1950s the working class, too, began to acquire these devices. It was at this time that there developed a concern for aesthetics as part of design.

Today they continue to play an important role in household chores. They have evolved both in technology and aesthetics and infinite varieties of price, quality, technology and design are available. There are different lines for every social class, from aesthetically simple, unsophisticated devices made only for functionality to products for demanding users who expect much more than basic functionality, who insist upon high aesthetic standards for socioeconomic contexts requiring both efficiency and aesthetics, which may even put them on exhibit as items of décor. An analogy could be made with luxury automobiles, whose aesthetic value is of primary importance, above and beyond their use for transportation, instilling social and psychological pleasure in the user while standing out above competing vehicles [8].

\subsection{Luxury}

Luxury is a concept associated with social pleasure. The origin of the world is from Latin: luxus, which can be recognized in the related words of many languages, lujo, lupus, liccht, lusso, luz, lumiére, light, illuminate. Light is splendor. According to Bourdieu [9], every luxury product should enchant, seduce, illuminate, light up, fascinate. It should be splendid, sumptuous, and should denote high quality. On the other hand, it is also superficial, ephemeral and useless. Luxury is appreciated by society today and has been throughout the history of mankind. It can also be considered a resource of a population, allowing someone to do something or possess something to which few other people have access. In this case, it functions as a social symbol of distinction.

In design, social symbols are important. Semiotics studies this communication bridge between the user and the object. A sign is not only something which represents a thing, but it is a structure which makes it possible for a receiver to learn something, to increase his or her knowledge [10]. When it comes to design and luxury, a sign is a message and aesthetics is the resource of distinction. According to Eco [11], "the message becomes an aesthetic function when it is structured ambiguously and presents itself as self-reflective, that is, when it pretends to attract the attention of the user firstly to the form itself." This means the object is interesting in itself; it calls attention to itself because it is different and people stop to admire it. Thus, it not only fulfills its useful function, but also fulfills the function of luxury. Luxury does not merely refer to costly items such as gems or precious metals. Technology can also be a luxury, for example when new technology is launched in the fields of automobiles and appliances and not everyone can gain access to them. However, once this technology is accessible to more social levels, it means these items have lost value in the market and the technology has been replaced by a new version. Another factor here is design. The very same technology can appear with a new face and thus satisfy the needs of the population that has access to the luxury market.

Meanwhile, Cutolo [12] mentions the close relationship between luxury and innovation, referring to another, even closer relationship between innovation and design.

Therefore, based on the above-mentioned comments, objects of design such as luxury household appliances and automobiles are the subject of this research, together with the attribution of metallic colors which the population of Guadalajara's Metropolitan Zone relates to the concept of luxury.

\section{Materials and Methods}

This is a cross-sectional study which implements the Focus-Group technique for the application of the evaluation. The sample was made up of 40 participants of both sexes. The inclusion criteria considered for the study required the participant to fit one of the following socioeconomic profiles: $\mathrm{C}$ intermediate, $\mathrm{C}+$ high intermediate or $\mathrm{A} / \mathrm{B}$ high, as specified in the tables of Mexican socioeconomic levels formulated by AMAI, Asociación Mexicana de Agencias de Investigación de Mercado (Mexican Association of Market Research Agencies) [13]. The individuals selected were of unspecified and varying professions and occupations and were all residents of the Guadalajara Metropolitan Zone.

The materials employed in the study were the following: a 
computer, a digital projector, response sheets and pencil. The paper and pencil questionnaire applied to the subjects was the Product Personality Profiling (PPP) analysis, which is a technique for Visual Product Evaluation [14] using a qualitative analysis. As its name indicates, the method submits the user to a projective test based on an image of a product.

The question proposed in the procedure was: imagine that each appliance is a person with a sophisticated life style. Now mark: What type of car would this person own? And later: What color would that car be? The images of the appliances were selected by design professionals. They were taken from products on the market, but the brands were not revealed in this document due to copyright issues. Only a description of the color of each product was given [15].

Types of cars in the questionnaire: Economic (Atos or similar), Compact (Chevy, Clio or similar), Intermediate (Aveo or similar), Standard (Sentra, Megane or similar), SUV (Nitro, Patriot or Koleos), Premium (Mercedes Benz
E280, Audi A6, Chrysler Grand Voyager), Luxury (BMW 730 and Mercedes SLK2), Vans (Journey, Suburban, Durango, Van Express), Freight-carrying (Traffic, Cangoo, F-350) [12].

Metallic colors in the questionnaire: silver, metallic sand, metallic red, metallic blue, metallic black, metallic grey, metallic white and metallic green.

A digital projector presented participants with six color images of home appliances (coffee maker, blender, microwave oven, refrigerator, stove and citrus juicer). These were shown one at a time and the association of each was registered on the assigned response sheet.

Here too, a descriptive statistics analysis was carried out, indicating that the population studied had an average age of 43.5 years, with 17 men and 23 women participating [15].

The following tables indicate the results obtained for the attribution of color and car to the CONCEPT OF LUXURY in each category of appliance through the application of Product Personality Profiling (PPP) analysis:

Tables. Attribution of COLOR and CAR in relation to the CONCEPT OF LUXURY in categories of appliances

\begin{tabular}{|c|c|c|c|}
\hline \multicolumn{4}{|c|}{ Table 1.} \\
\hline Appliance & \multicolumn{3}{|c|}{ Description of metallic color } \\
\hline & \multicolumn{3}{|c|}{$\begin{array}{l}\text { The metal looks like aluminum due to its very light silver color with subtle shades of blue. The } \\
\text { base is mahogany. }\end{array}$} \\
\hline Attributions of luxury \& car concept & $\%$ & Attributions of luxury \& color concept & $\%$ \\
\hline 1.Standard & 22.5 & 1.Metallic silver & 22.5 \\
\hline 2.SUV & 17.5 & 2.Metallic Black & 15 \\
\hline 3.Premium & 15 & 3.Metallic Grey & 12.5 \\
\hline \multicolumn{4}{|c|}{ Table 2.} \\
\hline Appliance & \multicolumn{3}{|c|}{ Description of metallic color } \\
\hline & \multicolumn{3}{|c|}{$\begin{array}{l}\text { The base of the blender is stainless steel; its color is dark silver with black reflections. The jar is } \\
\text { made of glass. }\end{array}$} \\
\hline Attributions of luxury \& car concept & $\%$ & Attributions of luxury \& color concept & $\%$ \\
\hline 1.SUV & 27.5 & 1.Silver & 22.5 \\
\hline 2.Premium & 20 & 2.Metallic Black & 17.5 \\
\hline 3.Luxury & 15 & 3.Metallic Sand & 17.5 \\
\hline \multicolumn{4}{|c|}{ Table 3.} \\
\hline Appliance & \multicolumn{3}{|c|}{ Description of metallic color } \\
\hline
\end{tabular}




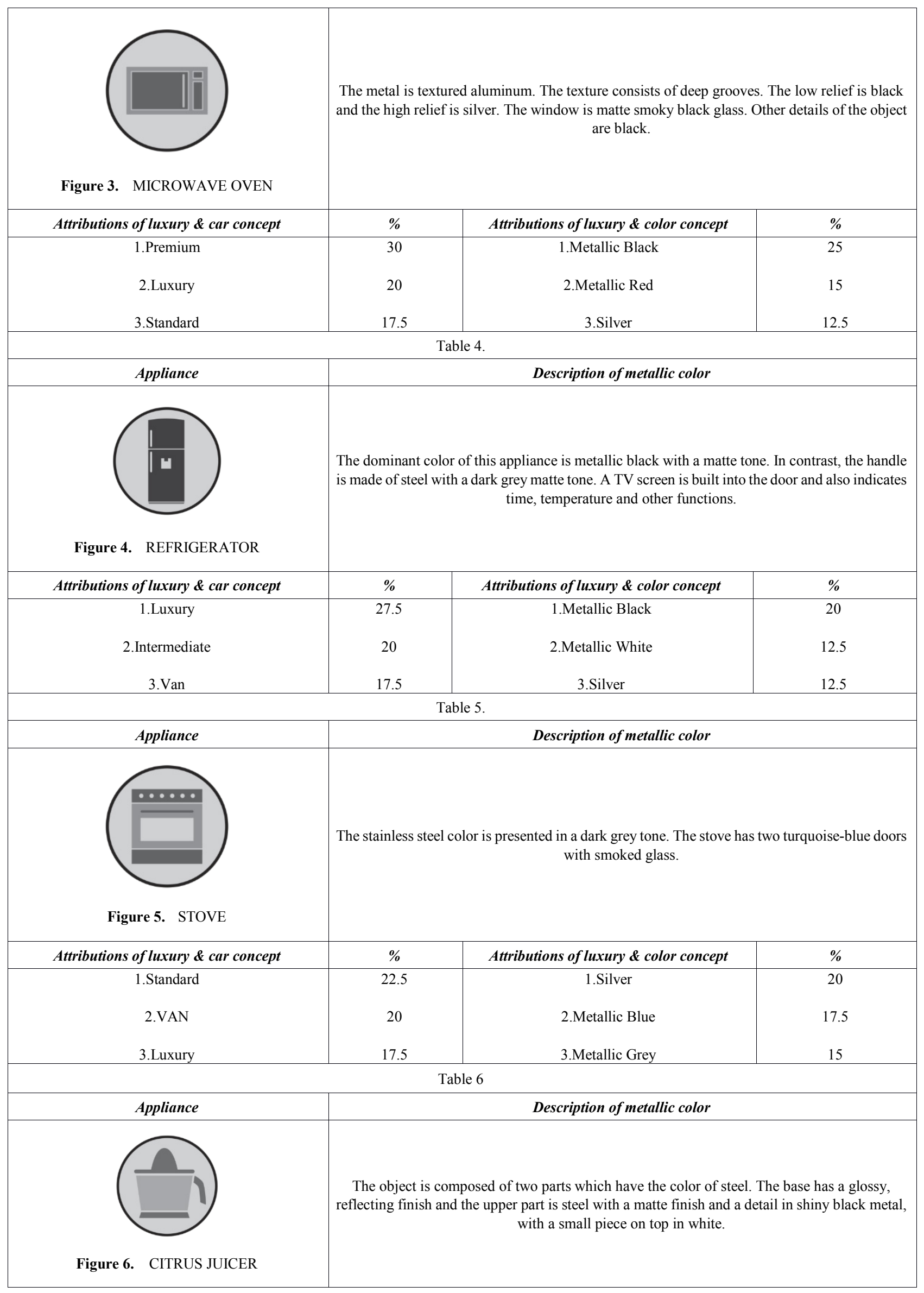




\begin{tabular}{|c|c|c|c|}
\hline Attributions of luxury \& car concept & $\%$ & Attributions of luxury \& color concept & $\%$ \\
\hline 1.Luxury & 22.5 & 1.Silver & 25 \\
2.Intermediate & 22.5 & 2.Metallic Sand & 12.5 \\
3.Premium & 20 & 3.Metallic Red & 10 \\
\hline
\end{tabular}

In accordance with what appears in the preceding tables, concerning the colors which the population of the Guadalajara Metropolitan Zone relates to the concept of luxury in appliances, the following was found:

a The color silver was associated with the concept of luxury in the first three positions of the six appliances. In four of them (coffee maker, blender, stove and citrus juicer), the preference was concentrated in a maximum of $25 \%$ and a minimum of $12.5 \%$.

b The color metallic black was associated with luxury in the microwave oven and refrigerator, with a maximum preference of $25 \%$.

c The colors metallic grey, metallic sand, metallic red, metallic white and metallic blue ranged interchangeably between second and third place as attributes of luxury among the six appliances, without significance, considering that the preferences varied between $17 \%$ and $10 \%$ for the metallic colors.

On the other hand, regarding the attributes of the concept luxury and car, the results indicate that:

a The association of this attribute in the refrigerator was $27.5 \%$ for a luxury car and $20 \%$ for the color metallic black.

b The association of this attribute in the citrus juicer was $22.5 \%$ for a luxury car and $25 \%$ for the color silver.

c The association of this attribute in the case of the microwave oven was $30 \%$ for a Premium car and $25 \%$ for the color metallic black.

d The association of this attribute in the blender was $27.5 \%$ for an SUV and 22.5\% for the color silver.

e The association of this attribute in the coffee maker and the stove was $25 \%$ for a Standard car in both of them and $22.5 \%$ for the color metallic silver (coffee maker) as well as $20 \%$ for the color silver (stove).

\section{Conclusions}

Based on the analysis carried out, it can be concluded that the population perceptually attributed the concept of luxury predominantly to the colors silver and metallic black. The meaning of metallic color in appliances since the 1930s still remains in effect today in designing these objects if they have been manufactured with materials such as steel, aluminum and other silvery metals.

At this time the same rule of the similarity of design and luxury between cars and appliances still applies. After so many years, it has remained intact. An infinite number of silver-colored objects continue to be manufactured for domestic use, especially for the kitchen. Silverware is still predominantly silver in color. This continues to be the trend, even in details such as cupboard handles, which appear modern or elegant if they are made of steel or aluminum.

As for the meaning of luxury associated with the color black, it should be pointed out that in some cultures black means death while in others it means elegance. This color was favored more in electronic devices than in appliances because of its masculine connotation. Nevertheless, it is also one of the colors which the study found to be highly associated with luxury, such as in the case of the refrigerator and the oven, which, many times, are accompanied by the color silver. This we could refer to as "the harmony of luxury," that is, the combination of the color silver with metallic black.

It should be mentioned that the color metallic green was found to have little association with luxury. This can be demonstrated contextually by the low production of appliances and cars of this color.

Finally, in the case of cars, the category associated with "Luxury" is linked to the perception of a Luxury car, a Standard, an SUV and a Premium, which are related to the colors Silver and Metallic Black, colors employed in the automobile industry.

\section{Note}

Images are designed by Karen Fernández Díaz.

\section{REFERENCES}

[1] E. Heller. Psicología del color, Como actúan los colores sobre los sentimientos y la razón, Gustavo Gilli, Barcelona, 2005.

[2] P. Sparke. Diseño y cultura una introducción, Desde 1900 hasta la actualidad, Gustavo Gilli, Barcelona, 2010.

[3] J.P. Favre. Color Sells your Package. Zurich: ABC Edition.

[4] Eiseman, L. (2000). Pantone. Guide to communicating with color. Nueva Jersey: Grafix Press

[5] Añaños, E., Estaún, S., Tena, D., Mas, M.T. y Valli, A. (2008). Psicología y Comunicación Publicitaria. Bellaterra : Universitat Autónoma de Barcelona, Servei de Publicacions.

[6] L. R. Prado and Rosa A. R.-Cinco, (2011) Effects of intensity and saturation on color associations in the Mexican. En: BIGGAM C.P., HOUGH C. A., KAY C. J. AND SIMMONS D.R. (EDS.). New directions in colour studies. Edit. John 
Benjamins Publishing Company. ISBN 978902721188 0, pp. 389-394.

[7] R. Pelta. El nuevo ángel del hogar. Electrodomésticos y publicidad en pensar la publicidad, Vol. 6, No. especial, 117-146, 2012.

[8] W. Green, P. Jordan. Human Factors in Product Design, Francis \&Taylor USA. 1999.

[9] P. Bourdieu. La Distinción: Criterios y Bases Sociales del Gusto, Editorial Taurus, Madrid, 1979.

[10] J. Warley. ¿Qué es la semiología? Didáctica de los signos y los discursos sociales, Editorial Biblos, Buenos Aires, 2011.
[11] U. Eco. La estructura Ausente. Introducción a la semiótica, Editorial Lumen, España,1986.

[12] G. Cutolo. Lujo y diseño, Santa \& Cole España, 2005.

[13] Available on line at www.amai.org NSE Niveles Socioeconómicos de México.

[14] D. Mc Donagh. A, Bruseberg. C, Haslam. Visual product evaluation: exploring users' emotional relationships with products. APPLIED ERGONOMICS, 2002.

[15] L. Ibarra. Proceso de Percepción y consumo de los objetos de diseño industrial, Caso de estudio: electrodomésticos de lujo en la vivienda (postgraduate theis). Universidad de Guadalajara, Jalisco, México. 2013. 